\title{
Matar negros, hacer blancos: Los colores y los nombres del enemigo en las guerras civiles de la España contemporánea
}

\author{
JoRDI CANAL \\ (EHESS, París) \\ Killing blacks, making whites: \\ Colors and names of the enemies in the civil wars \\ of the contemporary Spain
}

\begin{abstract}
RESUMEN
La guerra civil, omnipresente en numerosos países europeos a lo largo del siglo XIX, estuvo presidida por una guerra de colores. La lucha entre revolucionarios y contrarrevolucionarios se representó en colores, frecuentemente en fuerte contraste. Desde uno u otro bando, los colores y los nombres de colores eran usados para identificarse y reconocerse $y$ para identificar al oponente y distinguirse de él. En este artículo se encontrarán algunas aproximaciones a la utilización de nombres de colores para identificar a revolucionarios y contrarrevolucionarios en España en el siglo XIX y parte del siglo $X X$.

PALABRAS CLAVES

Revolución, contrarrevolución, carlismo, guerra civil, colores, blancos, negros, rojos.
\end{abstract}

\begin{abstract}
SUMMARY
The civil war, omnipresent in many

Europeans countries through out the XIX century, was presided by a war of colors. The fight between revolutionaries and counterrevolutionaries was represented by colors, frequently in a sharp contrast. For each side, colors, and names of colors were used for identifying and recognizing, and for distinguishing themselves from their opponents and to identify them. In this article you will find some approximations for the use of names of colors that identified revolutionaries and counterrevolutionaries in Spain in the XIX century and part of the $X X$ century.
\end{abstract}

\section{KEY WORDS}

Revolution, counterrevolution, carlismo, civil war, colors, whites, blacks, reds. 
El color, escribió Michel Pastoureau en un precioso libro titulado Bleu. Histoire d'une couleur (2000), no es un simple fenómeno natural, sino más bien una construcción cultural compleja. Se trata, en fin de cuentas, de un hecho de sociedad: "C'est la société qui " fait » la couleur, qui lui donne sa définition et son sens, qui construit ses codes et ses valeurs, qui organise ses pratiques et détermine ses enjeux.» Los colores deben ser abordados como un verdadero objeto histórico ${ }^{1}$. A diferencia de los medievalistas o de los modernistas, los historiadores de lo contemporáneo se han interesado más bien poco por estas cuestiones. La suposición de que se trata de un tema poco importante, anecdótico o trivial abunda, todavía hoy en día, en demasía. Los colores, sin embargo, eran importantes para los hombres y mujeres del pasado. En un trabajo dedicado al lenguaje de los gestos en la Italia moderna, Peter Burke mencionaba el proceso que ha tenido lugar de ampliación del territorio del historiador, incluyendo nuevos temas de interés, y las acusaciones de trivialización del pasado con que algunos lo han recibido. Burke proponía las siguientes respuestas a estas objeciones: reconocer, primeramente, que el peligro de trivialización existe, pero solamente cuando las cuestiones se investigan de manera aislada, sin relación con su contexto; en segundo lugar, relativizar y problematizar la propia noción de trivial -en el caso concreto que le ocupaba, el historiador afirmaba que los gestos no se tomaban a la ligera en la Europa moderna-; y, finalmente, en la estela de Sherlock Holmes, Sigmund Freud o Carlo Ginzburg, destacar la importancia de lo trivial, que suele aportar claves sobre lo supuestamente más importante².

La guerra civil, omnipresente en numerosos países europeos a lo largo del siglo XIX, estuvo presidida por una guerra de colores $^{3}$. La lucha entre revolucionarios y contrarrevolucionarios se representó en colores, frecuentemente en fuerte contraste: blancos contra azules, negros o rojos, banderas blancas contra banderas tricolores, boinas rojas contra rojos con o sin boina, lazos rojos contra lazos azules y blancos. Desde uno u otro bando, los colores y los nombres de colores eran usados para identificarse y reconocerse y para identificar al oponente y distinguirse de él. La injuria, el insulto y la descalificación no estaban ausentes en estos conflictos cromáticos. El color se fundía, en ocasiones, con la adscripción política. Eulalio Ferrer ha escrito que «la historia política española está marcada por los enfrenta-

1 Michel PAStOUREAU, Bleu. Histoire d'une couleur, París, Éditions du Seuil, 2000, pp. 7-11. La cita, en p. 9. Existe una versión del libro en formato bolsillo y sin ilustraciones: París, Éditions du Seuil, 2002. Cf., también, del mismo autor, Noir. Histoire d'une couleur, París, Éditions du Seuil, 2008; «Une histoire des couleurs est-elle possible? », Ethnologie française, 20-4, 1990, pp. 368-377, y Dictionnaire des couleurs de notre temps. Symbolique et société, París, Éditions Bonneton, 1992.

2 Peter BURKE, «El lenguaje de los gestos en la Europa moderna» [1991], en Formas de historia cultural [1997], Madrid, Alianza Editorial, 2000, pp. 87-89. Cf., asimismo, las reflexiones de Jordi CANAL, «Historiografía y sociabilidad en la España contemporánea: reflexiones con término», Vasconia, 33, 2003, pp. 11-27.

3 Jordi CANAL, «Guerra civil y contrarrevolución en España y en la Europa del sur en el siglo XIX», Ler História, 51, 2006, pp. 9-36. Una versión más reducida, en «Guerra civil y contrarrevolución en la Europa del sur en el siglo XIX: reflexiones a partir del caso español», en Ayer, 55, 2004, pp. 37-60. 
mientos de los colores» ${ }^{4}$. De hecho, desde los años de la década de 1830, color es sinónimo en tierras hispánicas de partido o facción política. En un texto publicado en 1865, con el título ¡Alerta, Pueblo Español! Folleto de actualidad que deben leer los blancos, los negros y los rojos, el autor, antes de pasar al análisis de los cinco partidos que en su opinión existían por aquel entonces en España (absolutista, moderantismo, progresistas, demócratas y Unión Liberal), se refería, por ejemplo, a los «intrigantes de todos los colores» ${ }^{5}$. El lenguaje político de los colores puede ayudarnos, sin duda alguna, a reconstruir y avanzar en una historia más compleja y global de la contrarrevolución ${ }^{6}$. El tema es vasto. No se pretende aquí, en ningún caso, agotarlo. En las páginas que siguen se encontrarán algunas aproximaciones a la utilización de nombres de colores para identificar a revolucionarios y contrarrevolucionarios en España en el siglo XIX y parte del siglo XX. Se han dejado a un lado, por tanto, aunque en ocasiones inevitablemente aparezcan, los colores de banderas, lazos, uniformes o boinas; solamente recibe atención el uso de los nombres de color para identificarse o para nombrar y caracterizar al enemigo. Resulta imposible estudiar la contrarrevolución sin tratar la revolución $-\mathrm{y}$, viceversa-, igualmente como es imposible estudiar un color sin ocuparse de los otros, en especial sus opuestos. En algunos países como Francia, este tema ha recibido algo de atención, como muestran los trabajos de Michel Pastoureau, Dominique Lejeune o Maurice Agulhon, entre otros, pero no en España ${ }^{7}$.

\section{BLANCOS, NEGROS Y ROJOS}

La larga guerra civil vivida en la España del siglo XIX, que enfrentó a carlistas y a liberales, fue también una guerra de colores: blancos contra negros ${ }^{8}$. Los historiadores no se han ocupado de este tema, pero, en cambio, las evidencias de que sí formaba parte de las vidas y preocupaba a los hombres y las mujeres de la época abundan. Dos novelas publicadas en la última década de la centuria pueden ilustrarnos sobre el antagonismo cromático: Paz en la guerra (1897), de Miguel de Unamuno, y Blancos y Negros. Guerra en la paz (1898), de Arturo Campión. Mientras que en la novela de Unamuno se observa la guerra y la paz durante la propia guerra —en este caso, la Segunda Guerra Carlista (1872-1876)_, en la del

${ }^{4}$ Eulalio FERRER, Los lenguajes del color, México, Instituto Nacional de Bellas Artes-Fondo de Cultura Económica, 1999, p. 298.

5 iAlerta, Pueblo Español! Folleto de actualidad que deben leer los blancos, los negros y los rojos, Madrid, Imprenta de F. Rivas, 1865, p. 4.

6 Cf. Jordi CANAL, «Repensar la historia de la contrarrevolución en la Europa del siglo XIX», en El carlismo en su tiempo: geografías de la contrarrevolución, Pamplona, Gobierno de Navarra, 2008, pp. 19-23.

7 Michel PASTOUREAU, Bleu. Histoire d'une couleur, y Noir. Histoire d'une couleur. Dominique LEJEUNE, La peur du «rouge» en France. Des partageux aux gauchistes, París, Belin, 2003. Maurice AGULHON, «Les couleurs dans la politique française», Ethnologie française, 20-4, 1990, pp. $392-398$. Este artículo fue reproducido en Maurice AGULHON, Histoire vagabonde, vol. III, París, Gallimard, 1996, pp. 170-188.

8 Cf. Jordi CANAL, «Guerra civil y contrarrevolución...». 
navarro Campión, casi contemporánea de la anterior, se trata de la guerra entre blancos y negros después de la guerra, esto es, en los tiempos de paz de la Restauración. La peculiar articulación entre historia e intrahistoria que Miguel de Unamuno nos brinda en Paz en la guerra permite ahondar en el uso popular de los vocablos «blanco» y «negro» para designar a los partidarios de uno u otro bando del conflicto fratricida del Ochocientos. El sermón del cura de aldea, que Ignacio oye en la iglesia, pongamos por caso, muestra claramente alguna de las bases del conflicto y, asimismo, alguna de las vías de su definición y extensión:

« ¡Siglo de las luces! ¡Mucho vapor, mucha electricidad! Y Dios, que es la electricidad y el vapor verdaderos... El ferrocarril lleva la corrupción a los más escondidos valles. Las familias apenas se recogen ya a rezar el santo rosario; y mientras el buen casero, apoyado en su laya, sobre la tierra regada con su sudor cuando se ha puesto el sol, a la oración, se quita la boina y reza; el negro allá, en su escritorio de Bilbao, adora el becerro de oro, y medita el engaño. ¡Cómo iban muriendo las buenas costumbres viejas! Por lo mismo Dios irritado, concitado en su rigor, mandaba sequías y chubascos, y epidemias al ganado; castigaba a todos, para que los buenos se alzaran en su defensa. ${ }^{9}$

En otro pasaje de la novela, Ignacio, tras semanas de marchas y contramarchas con las tropas carlistas, pasa por la aldea paterna, en donde se celebraba una romería:

«Salióle la tía Ramona a la puerta, y al verle llegar en armas no se atrevió a hacerle mudar de calzado. Abrazóle el tío, y llamándole aparte le expuso lo inconveniente que sería recibirle alojado allí mismo, en la casa misma que el jefe del batallón. Fuese a casa del primo Toribio, el mismo a cuya boda asistiera. Tenían ya un hijo, que berreaba en su cuna mientras los padres sudaban en la heredad, inocentes del curso de la historia, y a oscuras respecto a lo que fuese la guerra. Para ellos había guerra como pudiera haber tronada, o un año de sequía, o de epidemia en el ganado. ¡Los negros tenían la culpa de todo! Y lo peor de la guerra era la saca de raciones, el lento saqueo en los graneros del labrador pacífico, que maldito si entendía jota de la negrura de los negros, ni de la blancura de los blancos. ${ }^{10}$

Mientras tanto, los carlistas que permanecieron en Bilbao recibieron presiones y ataques por parte de los liberales. La madre de Ignacio se lo cuenta de la manera siguiente:

«Tu padre quiere que dejemos la tienda y nos vengamos por acá, más cerca de ti. Dice que no se puede resistir ya allí. ¡Jesús, Jesús! ¿Cuándo acabará esto? Esos negros tienen el alma de peñasco. Saben que no han de poder, y inada!, darnos que sentir. ${ }^{11}$

Un salto al campo contrario puede resultar muy interesante. La conversación que tiene lugar en casa de los Arana, tras el sitio de Bilbao, es ilustrativa:

\footnotetext{
9 Miguel de UNAMUNO, Paz en la guerra [1897], Madrid, Alianza Editorial, 1988, p. 100.

10 Ibíd., p. 136.

11 lbíd., p. 147.
} 
«En casa de Arana molieron a preguntas a un pariente de don Epifanio. Quedábales un consuelo, y era que si mal lo habían pasado dentro, fuera habría sido peor. Los liberales habían vivido de milagro, y los carlistas más divertidos que nunca. ¡Qué tertulias las de los pueblos, animadas por los emigrados carlistas de Bilbao! ¡Qué limonadas!

—QQué fanatismo, chico, qué fanatismo! ¡Qué sermones! Las iglesias parecían clubs o tabernas... Los negros por aquí, los negros por allí... Figúrate que por Pascua no se pudo vender a ningún precio un cordero hermoso, iporque era negro! Un día que entramos Matrolochu y yo en la iglesia, llena de gente, nos dejaron anchos anchos, por no tocar a unos negros. ${ }^{12}$

El odio de los blancos a los negros aparece nítidamente en varios fragmentos de Paz en la guerra. Uno de los personajes, Domingo, que estaba a punto de casarse cuando se fue a la guerra, afirma en la novela que lo que hace falta es «matar negros»: «¡Psé! Esto acabará pronto, y cuando les zurremos la badana me echaré la soga al cuello. Ahora a matar negros...» Y otro compañero añade: « $Y$ luego a hacer blancos.» Más adelante, en el mismo sentido, escribe Unamuno: "Otros vecinos, mujeres las más, desde las alturas del monte, les gritaban animándoles a que no dejaran vivo a un solo negro. ${ }^{13} \mathrm{El}$ papel de las mujeres en la novela es decisivo. Contrasta, curiosamente, con la ausencia de la mujer en las historias del carlismo ${ }^{14}$. A matar negros exhorta, asimismo, la madre de Juan José a los chicos:

«El día siguiente fue de completa alegría, pues encontraron a Juan José con su madre y comieron juntos todos. La madre de Juan José les recomendaba que mataran muchos negros. Josefa Ignacia sonreía mirando a su hijo. Gambelu se frotaba las manos augurando la próxima entrada en Madrid. ${ }^{15}$

No obstante, al final, blancos y negros acaban reuniéndose, en palabras de Miguel de Unamuno, en la «santa fraternidad de la muerte»:

«Reunidos unos y otros en el campo neutral, para dar sepultura a los muertos, habían abierto grandes zanjas en que los echaron como quien sotierra langostas, sin el último beso de sus madres, blancos y negros en la santa fraternidad de la muerte, a descansar para siempre en paz en el seno del campo de combate, regado con su sangre. Cayó sobre ellos con la tierra la última oración, la última lástima y después un inmenso olvido. ${ }^{16}$

La consumación del fratricidio, en vida, acaba por imponer un retorno, tras la muerte, a la fraternidad.

12 Ibíd., p. 229.

13 Ibíd., p. 155 y p. 157.

${ }_{14} \mathrm{Cf}$. Jordi CANAL, «El carlismo en España: interpretaciones, problemas, propuestas», Trienio, 49, 2007, p. 211.

15 Miguel de UNAMUNO, Paz en la guerra, p. 148.

16 Ibíd., p. 253. 
Si de la unamuniana Paz en la guerra pasamos a Blancos y Negros. Guerra en la paz, de Arturo Campión, podremos seguir observando el uso normal en la España del siglo XIX de los términos «blanco» para referirse a los partidarios del carlismo y «negro» para los del liberalismo (igualmente como ocurría en Francia con los blancos contrarrevolucionarios y los azules republicanos, inmortalizados por Alexandre Dumas en una obra algo olvidada, Les Blancs et les Bleus, de 1867$\left.1868^{17}\right)$. En un pasaje de esta novela de «tesis» - a la manera de José María de Pereda-, el abogado Ignacio Ostiz recibe dos cartas, una de un carlista y la otra de un liberal. El comentario del personaje resulta harto expresivo: « iVaya una coincidencia chistosa! Después del blanco, el negro; es imposible que las dos cartas hayan venido sin pegarse de bofetones, dentro de la misma saca. ${ }^{18}$ El final de la obra es, asimismo, muy sugestivo. Escribió Arturo Campión:

«Y es que los espíritus estaban cohibidos por la preocupación política, por la elección de diputados a Cortes que iba a verificarse el día siguiente. La incesante propaganda de mes y medio, había sembrado desconfianza y odio en los corazones. El recuerdo de los últimos sucesos aumentaba la audacia de unos, y el afán de desquite de otros. Blancos y Negros habían puesto sus ojos en Urgain, para repetir la mixtificación, y para impedirla. Ni siquiera le cabía al labrador el gusto de recoger pacíficamente su mísero bocado de pan. Ganchos y muñidores de ambos partidos recorrían las eras, torciendo las voluntades con la promesa, la dádiva y el engaño. Sobre el fiemo de las cuadras, campaba el fiemo, mil veces más pestilente, de la política española.

¿Cómo fue? No llegó a aclarase el punto. Disputó Selaya con el organista, o don José Joaquín con el notario. El caso es que dos eras contiguas comenzaron la disputa, y desde allí se corrió como incendio por rastrojo. A la amenaza replicaba la burla, al sarcasmo la ironía. El agravio político se envenenaba con el pus del agravio personal, y los antagonismos particulares presentaban sus ángulos a los del partido. Tantos gritos rajantes, tantas voces broncas, tantos improperios, tantos retazos de historia familiar, local, regional, provincial y nacional como allí resonaron, sobre las eras estercoladas, se resolvían en una frase única, fórmula y resumen supremos: «jmás eres tú!».

Vacío el cesto de las injurias, exhausto el desaguadero de los insultos, los hombres, enardecidos por el sol que en las venas inyectaba fuego, se lanzaron unos contra otros a puñadas, mordiscos y coces, rodando y revolcándose frenéticamente por el suelo.

Y cuando, al cabo, se logró restablecer el orden y llegó el caso de levantar los contusos y heridos, nadie hubiese podido decir quiénes eran los blancos y quiénes los negros, pues a todos les tiznaba y embadurnaba, parificándolos, desde la uña del pie hasta la punta del pelo, el líquido derramado por las eras. $>^{19}$

Como en una de las citas de la novela de Unamuno que hemos visto más arriba, aquí también blancos y negros acaban confundiéndose, en metáfora fraternal y/o fratricida.

17 Alexandre DUMAS, Les Blancs et les Bleus [1867-1868], París, Phébus, 2006.

18 Arturo CAMPIÓN, Blancos y Negros [1898], en Obras Completas, IX, Pamplona, Mintzoa, 1984, p. 254.

19 Ibíd., pp. 468-469. 
Los ejemplos podrían multiplicarse. Una obra estrenada en diciembre de 1893 en el Teatro Español, escrita por José Francos Rodríguez y Félix González Llana, llevaba por título Blancos y negros. La acción se situaba en un pueblo de Cataluña durante la insurrección realista de 1822. Al principio de la pieza teatral, dice Manuel, el posadero: «Hace unos cuantos años que los españoles no tenemos tiempo más que para rompernos la crisma en defensa de blancos o negros.» $\mathrm{Y}$, en la última escena, Pepa exclama, en una fórmula que nos recuerda las de Unamuno y Campión: « YYa corre junta la sangre de blancos y negros! jLa guerra civil consuma su obra! ${ }^{20}$. En algunas ocasiones se emplearon, en el siglo XIX, términos para definir opciones no claras entre el blanco y el negro, como «verdinegro» 0 "tornasolado» ${ }^{21}$. Existe también en España una utilización de la voz «negro» como sinónimo de «clerical» o «reacción» — muy especialmente si los jesuitas estaban de por medio-, asimilable a la que se hace en otros países católicos, pero que tuvo menor implantación precisamente como consecuencia de la fuerza de su aplicación injuriosa a los liberales. Este sentido se corresponde al que le dio el novelista Stendhal, en una Francia en donde este uso fue muy habitual, en Le Rouge et le Noir (1830). La Internacional negra, en la misma línea, fue una organización secreta católica, implantada en varios países europeos y dependiente directamente del Vaticano, que, en la década de 1870, intentó hacer frente al liberalismo, el socialismo y el nacionalismo; en México, en la época de la Cristiada, los grupos de mujeres enlutadas que integraban la Cruzada Femenina por la Libertad eran motejados como la «Langosta Negra»22. Sea como fuere, a los blancos y a los negros se les van a agregar en tierras hispánicas en el siglo XIX, como en innumerables otros países, los rojos, esto es, socialistas, demagogos e, incluso, republicanos ${ }^{23}$. El color rojo, al igual que el blanco, adjetivará también símbolos, agrupaciones y acontecimientos.

Existe en el caso español una clara evolución desde la confrontación blancosnegros de las guerras civiles del siglo XIX hacia el enfrentamiento blancos-rojos de la Guerra Civil de 1936-1939. Los rojos ya no eran solamente los socialistas, o los comunistas, sino que todos los partidarios de la Segunda República acabaron recibiendo este apelativo. "Rojo era nuestro segundo apellido", afirmaba la andaluza Francisca Adame, recordando la guerra civil de $1936-1939$ y la posguerra ${ }^{24}$. El

20 José FRANCOS RODRÍGUEZ y Félix GONZÁLEZ LLANA, Blancos y negros. Drama en tres actos y en prosa, Madrid, R. Velasco Impresor, 1893. Las citas, en p. 6 y p. 56.

${ }^{21}$ Cf. Demetrio CASTRO, «Jerigonzas y glosarios. Sobre el léxico político en la Revolución liberal», Ayer, 48, 2002, pp. 271-272.

22 Cf. Maurice AGULHON, «Les couleurs dans la politique française». Emiel LAMBERTS, ed., The Black International. L'Internationale noire (1870-1878), Lovaina, Leuven University Press, 2002. Agustín VACA, Los silencios de la historia: las cristeras, Guadalajara, Colegio de Jalisco, 1998, pp. 228-229. Para el siglo XX en Francia, cf. Annie MOLLARD-DESFOUR, Le dictionnaire des mots et expressions de couleur, XXe-XXle siècle: Le Noir, París, CNRS, 2005.

${ }^{23}$ Cf. María Paz BATTANER, Vocabulario político-social en España (1868-1874), Madrid, Real Academia Española, 1977, pp. 204-206.

${ }^{24}$ Palabras pronunciadas por Francisca ADAME el 30 de noviembre de 2007 en el Coloquio Internacional Historia y Memoria, celebrado en Granada. 
nombre «rojo» se carga de la negatividad que durante el siglo anterior había tenido «negro». Una negatividad que hace que algunos autores del bando antirrepublicano prefieran utilizar sinónimos como «colorado» para evitar tener que escribir la palabra «rojo»: Ernesto Giménez Caballero, por ejemplo, en Camisa azul y boina colorada (1939), afirmaba que el azul y el colorado eran «los colores españoles por esencia» y «los colores con que el pueblo de España llevaba desde siglos pintadas sus entrañas». Innumerables alusiones al colorado, mas ausencia total del rojo ${ }^{25}$. Cierto es, sin embargo, que, en la voluntad de aludir a los otros, al oponente o enemigo, al término «rojos» lo acompañaron otros vocablos, derivaciones o adaptaciones cromáticas del anterior, menos usuales y, en algún caso, algo más ofensivos: «rojillos», "rojazos», «bermellos», "bermellones», "rogelios», «colorados», «encarnados» —o en la forma «coloraos» y «encarnaos»—26. Tampoco los blancos eran a finales de la década de 1930, exclusivamente, los carlistas, o los tradicionalistas más en general, sino que se llegó a considerar como tales a todos los derechistas, a los llamados de manera más habitual «nacionales». Los blancos eran, en el drama de Alejandro Rey-Stolle, Rojo y español (1939), «los españoles de verdad» ${ }^{27}$. Francisco Franco oponía claramente, en octubre de 1937, a los «españoles rojos» y a los "españoles blancos»" ${ }^{28}$.

El 2 de octubre de 1936 se estrenó, en el Teatro Lírico de México, la tragedia Blancos y rojos (España 1936), obra de Eutiquio Aragonés. La acción estaba ambientada en una ciudad de Castilla, en 1936, durante la Guerra Civil. En el primer acto uno de los personajes, Leonarda, haciendo como si estuvieran hablando los dos bandos enfrentados, representados por Pablo y Rodrigo, decía:

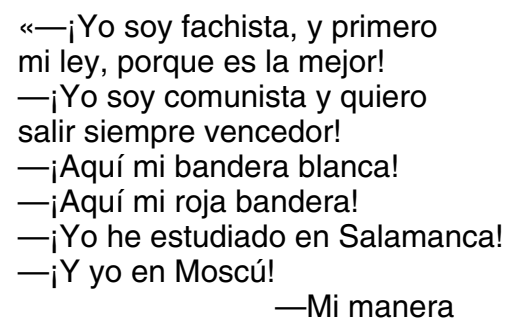

de saludar es mi cuño:

25 Ernesto GIMÉNEZ CABALLERO, Camisa azul y boina colorada, Madrid, Ediciones «Los Combatientes", 1939. Las citas, en p. 9 y p. 11.

${ }_{26}$ Rafael GARCÍA SERRANO, Diccionario para un macuto, Madrid, Editora Nacional, 1964, pp. 332-335.

27 Adro XAVIER [Alejandro REY-STOLLE], Rojo y español, Bilbao, El Mensajero del Corazón de Jesús, 1939, p. 71. Citado por Xosé M. NÚÑEZ SEIXAS, iFuera el invasor! Nacionalismos y movilización bélica durante la guerra civil española (1936-1939), Madrid, Marcial Pons, 2006, p. 260.

${ }_{28}$ Citado por Miguel A. REBOLLO TORÍO, Vocabulario Político, Republicano y Franquista (19311971), Valencia, Fernando Torres Editor, 1978, p. 101. He encontrado un único ejemplo claro de oposición entre rojos y azules, en lugar de blancos, que atribuyo a la sustantivación de un adjetivo cromático de connotación falangista (camisa azul, División Azul). Ramón LACADENA, Marqués de La Cadena, Entre rojos y entre azules, Zaragoza, Heraldo de Aragón, 1939. 
¡mi brazo es fuerte hasta vos!

- iY yo levanto mi puño

amenazante hasta Dios!...»29

La España blanca se estaba enfrentando a la roja, como describía el tradicionalista Antonio Pérez de Olaguer en Lágrimas y Sonrisas (1938):

«Estuve ya en la España roja de Barcelona y de sus pueblos anegados en odio. Vi caer, asesinados, a los más. Sufrí persecución. Salí, al fin, por la ruta de Génova. Voy ahora a la España blanca de Sevilla y de Burgos, a través de Tánger.»30

En otro libro, publicado en 1937 en la zona llamada nacional y significativamente titulado Estampas rojas y caballeros blancos, Vicente Gay contraponía a los caballeros blancos y a las bestias rojas. La guerra iniciada en 1936 no era, sostenía el autor, a diferencia de las carlistadas e incluso de la guerra colonial, una guerra civil, ya que «no existe entre los rojos y los blancos relación fraternal alguna»; los rojos no eran hermanos de los blancos, «porque han renegado de la Patria y han vendido a España al poder bolchevista» ${ }^{31}$. ¿Quiénes eran los blancos?, se preguntaba Vicente Gay. Consideraba como blancos, «dentro de toda la potencia gráfica del apelativo a los elementos de derecha, conservadores, monárquicos, liberales, republicanos históricos, etc.» Era el grupo en el que él se integraba, está claro: «Nosotros, los blancos...». Al otro lado estaban los «rojos», las «hordas rojas», la «ola criminal roja», los «caníbales rojos», la «revolución roja», la «bestia roja», la «chusma roja» o, entre otras expresiones parecidas empleadas en las páginas de este volumen escrito por un antiguo profesor de la Universidad de Valladolid y por aquel entonces delegado de Prensa y Propaganda en la España nacional, las «madrigueras rojas» ${ }^{32}$. El rojo, como recordaba Wenceslao Fernández Flores el 28 de mayo de 1939 en un artículo publicado en $A B C$, tenía también un olor especial. «Aquí huele a rojo», se decía. ¿A qué olían, así pues, los rojos? La respuesta del autor resulta muy interesante:

«El olor a rojo no puede ser encasillado entre ninguno de los olores conocidos. Es algo especial. Descompuesto, se encontraría en él el olor a bravío de las bestias montaraces, el de las sentinas, donde viajaban los emigrados, que es dulzón y se agarra a la garganta, el olor a botica, de las chinches gordas, el olor triste y húmedo de las rendijas donde anidan las cucarachas y otro elemento, un elemento especial, característico, que por no haber comparación, resulta, naturalmente, indescriptible.

(...).

\footnotetext{
29 Eutiquio ARAGONÉS, Blancos y rojos (España 1936). Tragedia en tres actos, en verso, estrenada con gran éxito el día 2 de octubre de 1936 en el Teatro Lírico de México, México D. F., Alrededor de América, s.f. [1937?], pp. 49-50.

${ }^{30}$ Antonio PÉREZ DE OLAGUER, Lágrimas y Sonrisas, Burgos-Sevilla, Ediciones Antisectarias, 1938 , p. 55.

${ }^{31}$ Vicente GAY, Estampas rojas y caballeros blancos, Burgos, Hijos de Santiago Rodríguez, 1937, p. 10.

32 Ibíd., p. 11 у р. 13.
} 
Sin duda, es olor de alma putrefacta, de corrupción espiritual, de sentimientos de carroña, pero no se sabe aún su quimismo.

Así olían ya las casas del Pueblo, los mítines del Frente Popular, las porterías y hasta infinidad de «honradas blusas», por muy bien lavadas que fuesen, pero nunca hasta ahora se dio el caso de una populosa capital entera encharcada en esa peste.

El olor a rojo es tan fuerte y típico, que creo posible distinguir a un marxista y aun seguir su rastro con un olfato poco ejercitado. El marxismo -religión de presidiarios, de fracasados, de envidiosos, de contrahechos, de vividores, de perezosos, de gente de cubil- tenía que oler así, precisamente: a conciencia podrida, que huele peor que una ballena muerta.

Porque el marxismo, materialista, es una doctrina intestinal, y sus eclosiones resultan mefíticas. ${ }^{33}$

La oposición blancos-rojos acabó por imponerse totalmente ${ }^{34}$. O casi, ya que el recuerdo del viejo enfrentamiento entre blancos y negros en el País Vasco y en Navarra, en el siglo XIX, siguió presente en las memorias. Esta circunstancia explica, por ejemplo, la aparición de la antigua guerra de colores en relatos como La higuera (2006), de Ramiro Pinilla. El cura Don Eulogio del Pesebre del Niño Jesús, párroco carlista de Getxo, ante la insistencia de algunos vecinos para que tome en consideración a Rogelio Cerón, el falangista que cuida celosamente de la higuera que da título a la novela, pregunta: «¿Quién es ese sujeto? ¿es de los blancos o de los negros?»35. O, también, en la última novela de Jon Juaristi, La caza salvaje (2007). Martín Abadía, el protagonista, en conversación con Juan Ramón Recondo, un joven perteneciente al Felipe -FELIPE era el nombre con el que se designaba a la organización política antifranquista Frente de Liberación Popular, que actuó a finales de los años cincuenta y en la década de los sesenta en España-, le comenta:

«La vida era bastante sencilla hace un siglo: los jaunchos carlistas en el interior, como los antepasados de tu mujer; la burguesía liberal en la costa. Cada treinta o cuarenta años se mataban entre ellos con fusiles de chispa, hasta que se aburrían y a otra cosa. Me divirtió ver a tu tío Pedro ayer, en mi humilde morada. Realmente, pensé, mucho ha debido de cambiar este país si un Andicoeche se digna visitar al hijo del práctico Abadía. ¿Cómo se toma tu familia política lo de tu militancia en el Felipe? Por lo que recuerdo, el abuelo de tu mujer se comía a los negros crudos. Me refiero a los liberales, aunque también podría aludir a los del Congo. Muy carlistas los Andicoeche, pero la casa se construyó con los dineros de la trata. La me-

${ }^{33}$ Citado por Francisco SEVILLANO, Rojos. La representación del enemigo en la Guerra Civil, Madrid, Alianza Editorial, 2007, pp. 171-174.

${ }_{34}$ Resulta paradójico, sin embargo, que el pretendiente Carlos Hugo de Borbón Parma y alguna de sus hermanas recibieran, en la segunda mitad del siglo XX, el apelativo «príncipe rojo» o "princesa roja». Debe ser puesto en relación, evidentemente, con el curioso «viraje ideológico» hacia posiciones socialistas del carlismo carloshuguista. Cf. Jordi CANAL, El carlismo. Dos siglos de contrarrevolución en España, Madrid, Alianza Editorial, 2000, pp. 370-389.

35 Ramiro PINILLA, La higuera, Barcelona, Tusquets, 2006, p. 144. 
Matar negros, hacer blancos: Los colores y los nombres del enemigo en las guerras...

moria colectiva en estos pueblos suele ser muy honda, sobre todo para lo que no es conveniente recordar. ${ }^{36}$

Negros del Congo y liberales negros, color de piel y color político: interesante juego de palabras, el de Jon Juaristi, en esta apasionante novela.

\section{EL ENIGMA DE LOS NEGROS}

¿Por qué los liberales eran llamados «negros» por sus oponentes? ¿Cuál es el papel del negro en esta particular guerra de colores? Mientras que los orígenes de la denominación «blancos» son más o menos conocidos - siempre vinculados, en Francia y en España, al color real, de los Borbones ${ }^{37}$-, los de «negros» lo son mucho menos. «Blancos» $y$ «negros» forman parte del nuevo vocabulario que se implanta en los años de la Revolución liberal española, en el que la preferencia por los términos despectivos para designar a las facciones rivales, como bien ha indicado Demetrio Castro, constituye un elemento muy significativo ${ }^{38}$. Un número no despreciable de las referencias a los orígenes y el significado de la palabra «negros» aplicada a los liberales coinciden en situarlos en la Primera Guerra Carlista (1833-1840) y relacionarlo con el color de los uniformes. Es lo que hizo Pío Baroja, por ejemplo, en Las mascaradas sangrientas (1927). En un pasaje de la novela, en el que se habla de Bertache y su partida, que estaban registrando a los ocupantes de un cochecito, escribía:

36 Jon JUARISTI, La caza salvaje, Barcelona, Planeta, 2007, p. 379.

37 En Portugal, en cambio, el principal color de la contrarrevolución fue, en el siglo XIX, el rojo (vermelho o encarnado). Este color fue utilizado como elemento de identificación —en algunas ocasiones asociado al azul, a imagen del «laço real», pero habitualmente solo-. Los contrarrevolucionarios se identificaban con el «vermelho» o «encarnado», ya que se trataba del color de la casa real de Braganza. El rojo se enfrentaba al azul y al blanco, colores de los liberales portugueses. A diferencia de lo que ocurría con los términos «blanc» en Francia y «blanco» en España, sin embargo, los sustantivos «vermelho» 0 «encarnado» no designaban a los contrarrevolucionarios portugueses. Los miguelistas no fueron nunca, por consiguiente, los rojos. Si en alguna ocasión había que distinguirles con un vocablo cromático se utilizaba, como en los países vecinos, el término «branco» («blanco»). Fue, no obstante, excepcional. Los intentos de sustituir unos colores por otros en los símbolos reales y nacionales fueron recurrentes. Vestirse con unos u otros colores constituyó una fórmula habitual de identidad partidaria. Algunas personas fueron asimismo encarceladas, acusadas de ofender y ridiculizar a la realeza, por colocar lazos rojos y azules en animales domésticos. Durante la guerra civil de 1828-1834 los dos bandos utilizaron los colores de las banderas y otros símbolos como elemento identificador y como nexo de unión entre el pasado y el presente. Lo hicieron, asimismo, en los años posteriores. No resulta extraño constatar, por consiguiente, que las acusaciones que impulsaron a la tropa, en su lucha contra las guerrillas miguelistas de la posguerra, a quemar la casa de un zapatero llamado Flores, residente en Riba Mouro, fueran las de prestar servicios a los guerrilleros y poseer muchos metros de tejido rojo. Cf. Maria Alexandre LOUSADA, «Nacionalismo e miguelismo (1823-1834)», en A Construçâo Social do Pasado, Lisboa, Associaçâo de Professores de História-Fundaçâo Calouste Gulbenkian-Universidade Nova de Lisboa, 1992, pp. 169 y 173. Isabel Nobre VARGAS, $A$ aprendizagem da cidadania em Portugal (1820-1823), Coimbra, Minerva, 1997, pp. 283-285. Maria de Fátima Sá e Melo FERREIRA, Rebeldes e Insubmissos. Resistências Populares ao Liberalismo (1834-1844), Porto, Ediçôes Afrontamento, 2002. António Manuel Monteiro CARDOSO, A Revoluçâo Liberal em Trás-os-Montes (1820-1834). O Povo e as Elites, Oporto, Ediçôes Afrontamento, 2007.

38 Demetrio CASTRO, «Jerigonzas y glosarios...», pp. 268-269. 
«Estaban haciendo el registro, cuando de una regata apareció un grupo de chapelgorris, con la boina roja y sin uniforme, y otro de peseteros a caballo, que vestían pantalón amarillento y chaqueta gris.

— ¡Los negros, vienen los negros! - gritaron los de la partida y los vecinos de las casas, asomados a las puertas y ventanas.

Eran los auténticos negros, porque al principio a los peseteros que llevaban el uniforme muy oscuro era a los que llamaban los negros.

Bertache y su gente se dispusieron a huir, y los liberales les soltaron una descarga cerrada.»39

Esta versión aparece en la mayoría de diccionarios y enciclopedias consultados. Según Jaime del Burgo, en su Bibliografía del siglo XIX. Guerras carlistas. Luchas políticas, con el nombre «negros» eran designados los liberales, en contraposición a los blancos o realistas; aunque en los inicios de la Primera Guerra Carlista esta denominación correspondiera sobre todo a los llamados peseteros y a los carabineros liberales, como consecuencia del color de sus uniformes, más adelante se extendió a todos los soldados del bando cristino ${ }^{40}$. Muy parecidas son las definiciones de José María Iribarren, en Vocabulario navarro -el autor hace también referencia al apodo «verdes», supuestamente aplicado a los liberales, por el color de los uniformes- o en la Enciclopedia General Ilustrada del País Vasco ${ }^{41}$. En casi todos los casos, la autoridad a la que se cita resulta ser Karl-Ferdinand Henningsen, un combatiente extranjero del ejército carlista que publicó en Londres, en 1836, el libro en dos volúmenes The Most Striking Events of a Twelvemonth's Campaign with Zumalacarregui in Navarre and The Basque Provinces ${ }^{42}$. La obra, traducida en múltiples ocasiones, fue muy influyente.

La oposición blancos-negros, sin embargo, era algo más antigua. Fue ya utilizada en ocasiones durante el Trienio Liberal (1820-1823) y con alta frecuencia en los años de la segunda restauración fernandina (1823-1833) para simbolizar el enfrentamiento entre realistas -y agraviados y, más adelante, carlistas- y liberales. En el Diccionario nacional o Gran diccionario clásico de la lengua española (18461847), Ramón Joaquín Domínguez escribía que las denominaciones políticas de «blancos» y «negros» se inventaron «en tiempo de los realistas» ${ }^{43}$. En este sentido, puede leerse en la Gaceta de Madrid del 24 de julio de 1823 un informe en el

39 Pío BAROJA, Las mascaradas sangrientas, Madrid, Caro Raggio (Serie Memorias de un hombre de acción), [1927], p. 243.

40 Jaime del BURGO, Bibliografía del siglo XIX. Guerras carlistas. Luchas políticas, Pamplona, s.ed., 1978 (2. ${ }^{\text {e ed. revisada), p. } 691 .}$

41 José María IRIBARREN, Vocabulario navarro, Pamplona, Diputación Foral de Navarra, 1952, p. 268 y p. 357. Enciclopedia General Ilustrada del País Vasco. Cuerpo A. Diccionario Enciclopédico Vasco, vol. IV, San Sebastián, Auñamendi, 1972, p. 433, y vol. XXXII, San Sebastián, Auñamendi, 1992.

42 Karl-Ferdinand HENNINGSEN, The Most Striking Events of a Twelvemonth's Campaign with Zumalacarregui in Navarre and The Basque Provinces, 2 vols., Londres, John Murray, 1836.

43 Ramón Joaquín DOMÍNGUEZ, «Blanco», en Diccionario nacional o Gran diccionario clásico de la lengua española, vol. I, Madrid, Establecimiento Léxico-Tipográfico de R.J. Domínguez, 1846, p. 264. 
que se comentaba que, en la ciudad de Zamora, a pesar de las amenazas del El Empecinado,

«llenos todos del mayor ardor y entusiasmo no se oían otras voces que las de viva el Rey, viva la religión, mueran los negros, ansiando por momentos se aproximasen más y más a la ciudad para pugnar con ellos y reducirlos a cenizas.»44

El 14 de octubre de 1823 se incluían, asimismo, en la Gaceta de Madrid unas alusiones a los tumultos provocados por el «populacho» tras el entierro de Rafael del Riego: «Las tropas francesas no han intervenido, porque parece que el tumulto no fue muy grande, y cuando los franceses se presentan en estas circunstancias para establecer el orden el populacho los llama negros. ${ }^{45}$ En uno de los apéndices del libro que dedicó a las sociedades patrióticas, Alberto Gil Novales incluía un pequeño vocabulario político-social de los años del Trienio Liberal. No faltaban, por supuesto, las voces «blancos» y «negros». Las equivalencias eran claramente indicadas: realistas los primeros, y liberales los segundos ${ }^{46}$. En este último caso, el autor aportaba un interesante ejemplo de Alicante, de julio de 1823:

«Negros, llaman los facciosos a los constitucionales, y nosotros llamamos a ellos cristianos nuevos; porque habiendo sido en el año 20 y 21 , y aun el 22 todos judíos por haber obedecido todos la Constitución, ahora que se han separado de nosotros, son cristianos nuevos todos los facciosos. ¡Y tan nuevos!»

En algunos casos, proseguía Gil Novales, la palabra «negros» iba acompañada de interesantes indicaciones, como en la hoja suelta Voluntarios del Rey (Navarrete, 30 mayo 1823), en donde se hacía referencia a los «negros hijos de Maquiavelo y Padilla» ${ }^{47}$.

La muchedumbre que acompañó a Fernando VII hasta su residencia en el Puerto de Santa María, a principios de octubre de 1823, vociferaba sin cesar: « ¡Viva el Rey! ¡Viva la Religión! ¡Muera la nación! ¡Mueran los negros!»48. Los gritos de «Mueran los negros» fueron harto frecuentes a lo largo del decenio siguiente. Sostiene Luis Alonso Tejada, con un punto de exageración, que desde la restauración absolutista de 1823 ya no se llamó de otra manera, sino negros, a los liberales ${ }^{49}$. La normal utilización del término aparece de forma nítida en los informes de 1825 estudiados por Juan Francisco Fuentes en el artículo que dedicó a los precedentes de la sublevación de Bessières. De esta manera, pongamos por caso, los agentes policiales que se paseaban por los barrios populares de Madrid para informar del estado de opinión de sus habitantes, escribían, el 17 de julio de

44 Gaceta de Madrid (Madrid), 46, 24 julio 1823.

45 Gaceta de Madrid (Madrid), 97, 14 octubre 1823.

46 Alberto GIL NOVALES, Las sociedades patrióticas (1820-1823), vol. II, Madrid, Tecnos, 1975, p. 975 у р. 979.

47 lbíd., p. 979.

48 Luis ALONSO TEJADA, Ocaso de la Inquisición en los últimos años del reinado de Fernando VII: Juntas de Fe, Juntas Apostólicas, Conspiraciones Realistas, Madrid, Zero, 1969, p. 67. 
1825: "Cuanto nos sucede de malo dicen estos infelices es por los negros, es por los negros, que se ven sostenidos por los gobernantes actuales». Las citas podrían acumularse $\mathrm{e}^{50}$. En otro orden de cosas, se cuenta asimismo que en aquellos postreros años del régimen absolutista el vicario general de Barcelona, Pere Josep Avellà, hizo pintar de blanco el rostro negro de la virgen de Montserrat que se veneraba en la catedral de aquella ciudad, ya que según él el negro era el color de los liberales ${ }^{51}$. Incluso el propio rey Fernando VII y su familia utilizaban el término como si fuera lo peor que uno podía llegar a ser considerado. Conocemos, en este sentido, la carta que le mandó su hermano, el infante Carlos María Isidro, en julio de 1826, en respuesta a un mensaje que el rey le había hecho llegar, a través de otra persona, sobre los planes de reforma que estaba por aquel entonces tomando seriamente en consideración. Entre otras cosas más, escribía:

«Dices enseguida que siempre has tenido franqueza conmigo, como que toda nuestra vida la hemos pasado juntos, pero que no me habías hablado de esto nunca porque no te tuviese por negro. ¡Válgame Dios, Fernando mío de mi corazón! ¿es posible que me digas esto?, ¿pues porque tú me hubieras hablado te había de haber hecho esta injuria?, te hubiera aconsejado lo que hubiera alcanzado en mi conciencia y en mi poco saber y hubiéramos estrechado más y más (si cabe) nuestro cariño y nuestro amor. Esto es lo que entonces y ahora y siempre estoy dispuesto a hacer. ${ }^{52}$

La reacción del infante Carlos María Isidro muestra a las claras la carga injuriosa que el término tenía para todos aquellos que lo aplicaban a sus enemigos políticos.

Igualmente como las palabras «negro»/«negros», en castellano, también las gallegas y portuguesas «negro»/«negros», las catalanas «negre»/«negres» y, de manera muy especial, las vascas «beltza»/«beltzak» se aplicaron a los liberales. En un extraordinario poema de origen carlista, escrito en 1839 por un sastre de La Selva del Camp, en el sur de Cataluña, se nos presentaba la Primera Guerra Carlista como una auténtica guerra civil nunca vista en aquella época. En una de las estrofas finales de la composición, podemos leer:

«Tot lo que ara havem passat

los nats no ho havien vist,

les revolucions com ara

no es troben en cap escrit,

49 Ibíd., p. 47. Me parece mucho más adecuado hacer referencia a una voz en franca expansión, como en las páginas introductorias de Javier FERNÁNDEZ SEBASTIÁN y Juan Francisco FUENTES, dirs., Diccionario político y social del siglo XIX español, Madrid, Alianza Editorial, 2002, p. 42.

50 Juan Francisco FUENTES, «Madrid, en vísperas de la sublevación de Bessières», en Revisión de Larra (¿Protesta o revolución?), París, Les Belles Lettres, 1983, pp. 99-113. La cita, en p. 104.

51 Cf. Josep FONTANA, De en medio del tiempo. La segunda restauración española, 1823-1834, Barcelona, Crítica, 2006, p. 91.

52 Carta citada por Antonio Manuel MORAL RONCAL, Carlos V de Borbón (1788-1855), Madrid, Actas, 1999, p. 214. 
guerra civil, oh, què horror!, carlistes i lliberals mataven i deshonraven encara que fossen germans.»

El sustantivo catalán «negre» (negro) es usado en alguna ocasión en el poema, siempre como sinónimo de liberal:

«tots voldran ara ser bons, ningú voldrà ara ser negre, tots temen a la carreta»53

Todos querrán ser ahora buenos y nadie querrá ser negro, escribía el sastre, si vence su estimado pretendiente Carlos V, pues todos temen las represalias. Las canciones en lengua vasca, tanto de la Primera como de la Segunda Guerra Carlista, están llenas de referencias a los negros. Sirvan como ejemplo un par de fragmentos de la larga composición titulada Zumalakarregi, 1835:

«Ez du oste handiak baratzen karlista,

Badoa bai superat, xorrotx baioneta,

Ibai handiz, odola badoa landetan

Beltz bat ez dago xutik heien aldaketan.

Ez sen gudukari bat karlisten artean,

Gorritua ez zenik, beltzen odolean;

Hire ezpata horri, suzko jenerala,

Gudu ondoan zarikon oraino odola.» ${ }^{54}$

Pero no solamente lo están las canciones, sino textos varios de la época. En un artículo del periódico carlista La Esperanza, de octubre de 1869, afirmaba un corresponsal:

«A bien que a estos honrados y religiosos vecinos no les engañarán [los liberales] porque tienen un distintivo infalible: es beltzac, argumento concluido; es ya capaz de cualquier cosa; el demonio encarnado. Y no van errados, porque la «he-

53 Diversió de realistes i desengany de liberals. Un poema carlí de la Selva del Camp, edición de Pere ANGUERA y Magí SUNYER, Barcelona, Ajuntament de la Selva del Camp-Publicacions de l'Abadia de Montserrat, 1991, p. 82 y p. 74.

54 Trad.: «Las multitudes no paran al carlista, la bayoneta afilada marcha hacia el fuego. En grandes ríos, corre la sangre por los campos: no queda un liberal en pie en las inmediaciones. No había un guerrero entre los carlistas, que no se hubiera manchado con la sangre de los liberales; esa tu espada, fogoso general, chorreaba de sangre mucho después de la batalla.» Jean HARITSCHELHAR, «Quelques chansons basques de la première guerre carliste (1833-1839)", en Euskal Herria (1789-1850). Actes du colloque international d'Etudes Basques, Bayona, Société des Amis du Musée Basque, 1978, p. 209; y Joseba AGIRREAZKUENAGA, «Antología de versos, canciones y sonetos relacionados con los fueros, la guerra y el convenio de Bergara», en Joseba AGIRREAZKUENAGA y José Ramón URQUIJO, eds., 150 años del Convenio de Bergara y de la Ley del 25-X-1839, Vitoria, Eusko Legebiltzarra-Parlamento Vasco, 1990, p. 524. Cf. también Antonio ZAVALA, Karlisten Leenengo Gerrateko Bertsoak, Tolosa, Auspoa, 1992. 
rejía política», que bien pronto puede ser religiosa, a que los liberales rinden culto, tiene que arrastrarles irresistiblemente a mil males funestos... Un liberal es capaz de hacer todo lo que al más ilustrado demonio le puede ocurrir, y aun dejarle haciendo cruces.»55

«Beltza» equivale, sostiene Luis Michelena, a liberal, tanto durante como después de las guerras carlistas ${ }^{56}$. Interesante resulta constatar la abundante utilización de esta palabra en el caso vasco. Y, asimismo, su larga pervivencia, aunque con algunos cambios: en la década de 1970, Beltza fue el seudónimo de un autor, Emilio López Adán, que escribió, entre otros, el libro Del carlismo al nacionalismo burgués ${ }^{57}$; en la actualidad, «beltza» es el nombre denigrativo que recibe el miembro de las fuerzas antidisturbios de la policía autónoma vasca.

En el caso portugués, los liberales también fueron motejados por sus oponentes como negros. El paralelismo con el caso español es evidente y la hipótesis más plausible apunta a una importación lusa desde el país vecino en los primeros años de la década de 1820. En un informe de julio de 1823, sobre Freixo de Espada à Cinta, en Trás-os-Montes, se indicaba que los realistas aludían a sus oponentes «tratando-os por nome de negros, e mais nomes injuriosos que se lembrâo". Los mueras a negros y constitucionales abundaron en aquellos años. Según António Manuel Monteiro Cardoso, el término «negros» fue muy utilizado para designar a los constitucionales hasta 1828, momento en el que empieza a prevalecer la denominación «malhados» 58 . «Malhados» 0, también, «cacarras» y «pedreiros" se usaron mucho; en el otro campo, los liberales motejaban como "corcovas», "corcundas» o "carcundas" a los contrarrevolucionarios - del portugués y gallego "corcunda» o "carcunda», alteraciones de "corcova» (joroba, jorobado, egoísta), derivó y se extendió precisamente, ayudado por la coincidencia fonética con "carlista», el término español «carcunda» y, asimismo, la abreviación jergal «carca»- ${ }^{59}$. Sin embargo, «negros» continuó formando parte del vocabulario antiliberal portugués. E, incluso, la combinación «negros malhados» 0 «malhados negros» no se convierte en excepcional. Maria de Fátima Sá e Melo Ferreira cuenta, por ejemplo, que en un pequeño motín popular que tuvo lugar en septiembre de 1834 en la aldea de Cardigos, concejo de Vila-da-Rei, en la provincia de Beira Baixa, se escucharon vivas a Dom Miguel y se llamó a los soldados liberales

55 La Esperanza, 23 octubre 1869, citado en Vicente GARMENDIA, La ideología carlista (1868-1876). En los orígenes del nacionalismo vasco, San Sebastián, Diputación Foral de Guipúzcoa, 1985, p. 76.

${ }_{56}$ Luis MICHELENA, Diccionario General Vasco. Orotariko Euskal Hiztegia, vol. IV, Bilbao, Real Academia de la Lengua Vasca/Euskaltzaindia, 1990, p. 639.

57 BELTZA [Emilio LÓPEZ ADÁN], Del carlismo al nacionalismo burgués, San Sebastián, Txertoa, 1978.

${ }_{58}$ Cf. António Manuel Monteiro CARDOSO, A Revoluçâo Liberal em Trás-os-Montes..., p. 176.

59 Cf. Joan COROMINAS y José A. PASCUAL, Diccionario crítico etimológico castellano e hispánico, vol. I, Madrid, Gredos, 1980, p. 864. Isaac Alonso ESTRAVÍS, Diccionário da língua galega, Santiago de Compostela, Sotelo Blanco Edicións, 1995, p. 293. María MOLINER, Diccionario de uso del español, vol. I, Madrid, Gredos, 1981, p. 520. José María IRIBARREN, Vocabulario navarro, p. 113 Demetrio Castro sugiere la posibilidad de emparentar "carcunda» con un término español usado en el siglo XVIII, «carcuezo». Demetrio CASTRO, «Jerigonzas y glosarios...», pp. 272-273, n. 23. 
«malhados negros» ${ }^{60}$. En cualquier caso, el fracaso de los miguelistas en $1834 \mathrm{im}$ plicó una pérdida progresiva de significado de la oposición rojo-negro. El rápido declive de los miguelistas, sobre todo si lo comparamos con lo ocurrido con los legitimistas franceses o con los carlistas españoles, explica la desaparición de esta concreta guerra de colores y, asimismo, la consiguiente atribución no problemática, con el paso del tiempo, del rojo a los republicanos y socialistas ${ }^{61}$.

Si el origen de la identificación de los liberales como negros en la Primera Guerra Carlista no resulta convincente, como acabamos de ver, tampoco lo es un significado que apunte exclusivamente al color de los uniformes. He escrito «exclusivamente» de manera consciente, puesto que no resulta excluible que el color de los uniformes usados en la carlistada contribuyera a afianzar la denominación «negros». Pero, como quiera que sea, el significado primigenio debía ser otro algo distinto. El tono casticista del texto alicantino de julio de 1823, que reprodujo Alberto Gil Novales en Las sociedades patrióticas y que se ha citado más arriba, puede colocarnos sobre otra pista. Las alusiones a «negros», «facciosos», «judíos» y «cristianos nuevos» no pueden pasar desapercibidas ${ }^{62}$. A reflexiones parecidas nos invitan las alusiones que se ponen en boca de los carlistas, en una obra de teatro inédita del catalán Josep Güell i Mercader titulada De Somorrostro a Bilbao (1874), según las cuales «los liberales o sean los negros son todos judíos o hijos de judíos» ${ }^{63}$. En una jota catalana se asimilaban también los liberales a los musulmanes:
«A la jota, jota, Verge moreneta,
a la jota, jota, patró dels cristians,
a la jota, jota, doneu-nos auxili,
que en eixa terra los moros han tornat.» ${ }^{64}$

Los moros han vuelto, rezaba esta canción. Las referencias al demonio y a la herejía no podían faltar tampoco, como quedaba claro en el texto ya reproducido de un corresponsal del periódico carlista La Esperanza, de octubre de 1869. Resulta posible pensar que referirse a un liberal como negro no tuviese nada que ver, como mínimo inicialmente, con el color de su uniforme, sino con el color de su alma, con la pureza al fin y al cabo. El ya citado Ramón Joaquín Domínguez

60 Maria de Fátima Sá e Melo FERREIRA, Rebeldes e Insubmissos..., p. 143. António Manuel Monteiro Cardoso cita, en su tesis doctoral, una utilización curiosa del término peyorativo «negros» desde el propio campo liberal, contraponiendo a los realistas ladrones con los negros, que eran hombres honrados. La mujer que lo dijo, Maria Correia, esposa de un preso liberal de Chaves, fue detenida por ello. António Manuel Monteiro CARDOSO, A revoluçâo liberal em Tras-os-Montes (1820-1834). O povo e as elites, Lisboa, tesis doctoral ISCTE, 2004, p. 551, n. 373.

61 Cf. Augusto FUSCHINI, Fragmentos de memorias. Liquidaçôes políticas. Vermelhos e azues, Lisboa, Companhia Typographica, 1896. Manuel Pinheiro CHAGAS, Vermelhos, Brancos e Azues, Lisboa, C.S. Afra \& C. ${ }^{a}$, [187?], s.p.. Francisco da Rocha MARTINS, Portugal dos nossos dias. Vermelhos, brancos e azuis. Homens de Estado, Homens de Armas, Homens de Letras, 4 vols., Lisboa, Vida Mundial Editora, 1948-1951.

62 Citado por Alberto GIL NOVALES, Las sociedades patrióticas..., p. 979.

63 Cf. Mercè COSTAFREDA, «El teatre anticarlí de Güell i Mercader», en Josep M. SOLÉ I SABATÉ, coord., Literatura, Cultura i Carlisme, Barcelona, Columna, 1995, p. 150.

64 Citado por Vicente GARMENDIA, La ideología carlista (1868-1876)..., p. 76. 
ofrecía en su diccionario de mediados del siglo XIX, entre algunas otras, estas dos definiciones de negro: «Malvado, perverso, hablando del alma, del corazón, de los sentimientos», y, en tanto que acepción política, «Epíteto dado por los miserables serviles, esclavos de su misma estupidez, a los liberales, cuya elevación de ideas los coloca en un rango muy superior a aquellos fanáticos»". ${ }^{65}$ La segunda definición no deja dudas, está claro, sobre el lado ideológico en el que se encontraba el autor. La expresión "tener el alma negra» fue bastante habitual en el siglo XIX. Sirva como ejemplo una cita del noveno de los Episodios Nacionales de Benito Pérez Galdós, Juan Martín el Empecinado (1874), cuando el famoso guerrillero que da título al volumen le espeta a mosén Antón, que había sido capturado tras haberle traicionado, pasándose a los franceses: «Dime, alma más negra que la de Satanás: ¿hay algún castigo que sea para ti más terrible que la muerte?»66 La expresión, que se ha ido haciendo cada vez más rara en España con el paso de las décadas, sigue siendo habitual en la actualidad, por ejemplo, en algunos países del continente americano ${ }^{67}$.

No sería, por supuesto, la única muestra de vocabulario casticista que el campo tradicionalista utilizaría en el siglo XIX. Piénsese, por ejemplo, en la palabra «mestizo" con la que los carlistas e integristas insultaban en la segunda mitad de la centuria a los católicos liberales, es decir a los católicos no suficientemente puros en su modo de ver. Los componentes casticistas de la política y la ideología españolas del siglo XIX son más importantes de lo que habitualmente se ha sostenido68. Pero volvamos, ahora, a los años 1820. Uno de los fenómenos que marcaron los inicios de la segunda restauración absolutista fueron la represión y las depuraciones. En la época, la depuración recibía otro nombre, el de purificación —el empleado público estaba obligado a «purificarse» $y$, a tal efecto, se crearon las juntas de purificaciones-, de nítido simbolismo. Jean-Philippe Luis escribe que «le choix de ce mot dénotait un contenu symbolique clair, conforme aux souhaits de tous ceux qui voulaient extirper le libéralisme de la société comme on extrait un corps étranger.»"99 Mientras que el blanco debía confirmar su real (o realista) pureza, el negro, el liberal o «liberalizante», que no puede ser, por definición, puro, pasaba a convertirse, en palabras de los contemporáneos, en impurificado. Ser negro va a ir convirtiéndose en la manera de nombrar al otro, en la forma de designar injuriosamente al enemigo, esto es, al liberal, que es justo lo contrario de blanco y de puro. Aunque las raíces de la identificación se pierdan con el paso de los años y nuevas connotaciones se sumen o reemplacen a las antiguas, el éxito del vocablo estaba asegurado.

65 Ramón Joaquín DOMíNGUEZ, «Negro», en Diccionario nacional o Gran diccionario clásico de la lengua española, vol. II, Madrid, Establecimiento Léxico-Tipográfico de R.J. Domínguez, 1847, p. 1250.

66 Benito PÉREZ GALDÓS, Juan Martín el Empecinado (Episodios Nacionales, 9) [1874], Madrid, Alianza Editorial, 2002, p. 200.

${ }^{67}$ Cf. José APARICIO BERNAL, «Lo negro y lo blanco», Monte adentro (Penonomé, Panamá), 64, 7 junio 2007, [p. 1].

${ }^{68}$ Cf. Christiane STALLAERT, Etnogénesis y etnicidad en España: una aproximación histórico-antropológica al casticismo, Barcelona, Proyecto A, 1998.

69 Jean-Philippe LUIS, L'utopie réactionnaire. Épuration et modernisation de l'État dans l'Espagne de la fin de l'Ancien Régime (1823-1834), Madrid, Casa de Velázquez, 2002, p. 64. 